in vivo $34: 3441-3449(2020)$

doi:10.21873/invivo. 12183

\title{
Impact of Hormone Receptor Status on the Behaviour of HER2+ Breast Cancer
}

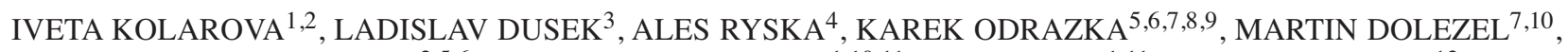 \\ JAROSLAV VANASEK ${ }^{2,5,6}$, BOHUSLAV MELICHAR ${ }^{1,10,11}$, JIRI PETERA ${ }^{1,11}$, TOMAS BUCHLER $^{12}$, \\ MILAN VOSMIK $^{1,11}$, KATARINA PETRAKOVA ${ }^{13}$, PETRA TERAROVA ${ }^{7,14}$, ZDENA VILASOVA $^{5}$ and JIRI JARKOVSKY ${ }^{3}$ \\ ${ }^{1}$ Department of Oncology and Radiotherapy, University Hospital Hradec Kralove, Hradec Kralove, Czech Republic; \\ ${ }^{2}$ Faculty of Health Studies, Pardubice University, Pardubice, Czech Republic; \\ ${ }^{3}$ Institute of Biostatistics and Analyses, Faculty of Medicine, Masaryk University, Brno, Czech Republic; \\ ${ }^{4}$ The Fingerland Department of Pathology, Charles University Medical Faculty \\ and University Hospital Hradec Kralove, Hradec Kralove, Czech Republic; \\ ${ }^{5}$ Oncology Centre, Multiscan, Pardubice, Czech Republic; \\ ${ }^{6}$ Department of Clinical and Radiation Oncology, Pardubice Hospital, Pardubice, Czech Republic; \\ ${ }^{7}$ Department of Oncology, First Faculty of Medicine, Charles University, Prague, Czech Republic; \\ ${ }^{8}$ Department of Radiotherapy and Oncology, Third Faculty of Medicine, \\ Charles University, Prague, Czech Republic; \\ ${ }^{9}$ Institute for Postgraduate Medical Education, Prague, Czech Republic; \\ ${ }^{10}$ Department of Oncology, Palacky University Medical School \& Teaching Hospital, Olomouc, Czech Republic; \\ ${ }^{11}$ Department of Oncology and Radiotherapy, Faculty of Medicine in Hradec Kralove, \\ Charles University, Hradec Kralove, Czech Republic; \\ ${ }^{12}$ Department of Oncology, First Faculty of Medicine, \\ Charles University and Thomayer Hospital, Prague, Czech Republic; \\ ${ }^{13}$ Department of Comprehensive Cancer Care, Masaryk Memorial Cancer Institute, Brno, Czech Republic; \\ ${ }^{14}$ Department of Oncology, General University Hospital in Prague, Prague, Czech Republic
}

\begin{abstract}
Background/Aim: The study aimed to evaluate differences in the overall survival of HER2+ breast cancer patients treated with regard to their hormone receptors negativity or positivity. We evaluated a cohort of patients treated with trastuzumab in the Czech Republic. Patients and Methods: The present study is a retrospective analysis of patients whose data were recorded in a nationwide non-interventional, postauthorisation database BREAST. After propensity score matching of data, the cohort included 4,532 patients. Results: A significant difference in overall survival (OS) of the entire cohort was found between patients with and without hormone
\end{abstract}

This article is freely accessible online.

Correspondence to: Jiř́ Jarkovský, Institute of Biostatistics and Analyses, Faculty of Medicine, Masaryk University, Kamenice 3, Brno, Czech Republic. Tel: +42 0549494203, e-mail: jarkovsky@iba.muni.cz

Key Words: Breast cancer, triple positive, HER2- positive, hormone receptors, overall survival, trastuzumab. dependence. The OS was significantly higher in the group of patients with hormone receptor-positive $(H R+)$ tumours in the following cohorts: patients treated with neoadjuvant therapy, patients with advanced disease, G2 tumours, stage III and IV and in patients with stage II and III of G2 tumours. Conclusion: Increased OS rates were found in several subgroups of patients with HR+/HER2+ tumours compared to those with HR/HER $2+$ tumours. Better outcomes of HR+/HER $2+$ patients were only observed in the first four/five years of follow-up, and the differences disappeared over time.

Breast cancer is an example of malignant tumour in which clinical behaviour and treatment options are fundamentally affected by the biological characteristics. The presence of hormone receptors (HR) and human epidermal growth factor receptor (HER)-2 is a principal factor determining the clinical management. Hormone receptor-positive (HR+) tumours are found in approximately 3 out of 4 breast cancer patients (1) whereas HER2 positivity is identified in about $15 \%$ of breast cancer patients. The negative prognostic significance of HER2 positivity was reported by Slamon in 1987 (2). 
HER-2 is a member of a family of transmembrane tyrosine kinase receptors [together with HER-1 (EGFR), HER-3 and HER-4] and a universal partner for heterodimerization with other members of HER receptor family. The amplification of the gene $c-e r b B-2$ resulting in overexpression or of HER-2 protein stimulates tumor growth, invasion and tumor cell survival by activation of several signaling pathways. HER-2 positive breast cancer is clinically and biologically heterogeneous disease (3-5). Triple-positive breast cancer (TPBC), i.e. HER2-positive (HER2+), ER-positive (ER+) and PR-positive $(\mathrm{PR}+)$ breast cancer, has been sometimes referred to as a specific subgroup of breast tumours (6-8). The unique biological properties of TPBC are caused by a crosstalk between HER2 and HR signalling pathways (9).

The present study aimed to analyse the difference between the overall survival (OS) of HR positive and HR-negative (HR-) HER2+ patients who were treated with trastuzumab. A cohort of breast cancer patients who had been included in a nationwide Czech research database and treated with targeted therapies was used, and an analysis comparing groups of patients with and without expression of hormone receptors was performed. The patient cohort structure was balanced by propensity score matching with respect to age and grade prior to analysis, otherwise the significance of hormone dependence on treatment outcomes could not be established properly.

\section{Patients and Methods}

Patient cohort and methodology. The analysis was based on data on all HER2+ patients who, on 8 January 2018, had a valid record in the BREAST research database, were or had been treated with targeted therapies in the Czech Republic and for whom data on hormone receptors status were available, andHER2 positivity was confirmed.

HER2 status was tested immunohistochemically in pathology laboratories where the primary histological diagnosis was made. All cases diagnosed locally were sent to one of the so-called reference laboratories where HER2 status was confirmed by CE-IVD certified immunohistochemical tests. Cases with confirmed $3+$ positivity were regarded as positive. Cases with $2+$ positivity were subsequently confirmed by in situ hybridization - of these cases, only those with amplification of c-erb-B2 gene were regarded as HER2 positive.

Hormone receptor status was diagnosed immunohistochemically. As the cohort was collected over longer period of time, the cut-off values for designation of tumour as ER/PR positive have changed and different values in the range between 1 and $10 \%$ were used as a threshold. Thus, all cases included in the TPBC cohort show at least $1 \%$ expression of ER and PR. The analysis included data on patients who were treated with trastuzumab in adjuvant, neoadjuvant or advanced disease therapy settings. Chemotherapy, radiotherapy and/or endocrine therapy was given to patients at the physician's discretion.

Matching the cohorts in age and grade. Out of 6,122 patients who met the above-mentioned criteria, a total of 4,532 patients were
Table I. Basic patient characteristics after propensity score matching.

\begin{tabular}{|c|c|c|}
\hline & $\begin{array}{l}\text { HR negative } \\
(\mathrm{n}=2,268)\end{array}$ & $\begin{array}{l}\text { HR positive } \\
(\mathrm{n}=2,264)\end{array}$ \\
\hline \multicolumn{3}{|l|}{ Age at diagnosis (years) } \\
\hline Median (range) & $57(20-88)$ & $57(23-85)$ \\
\hline \multicolumn{3}{|l|}{$\begin{array}{l}\text { Menopausal status at } \\
\text { diagnosis, } \mathrm{n}(\%)\end{array}$} \\
\hline Premenopausal & $644(28.4)$ & $760(33.6)$ \\
\hline Postmenopausal & $1,623(71.6)$ & $1,504(66.4)$ \\
\hline \multicolumn{3}{|l|}{$\begin{array}{l}\text { Histological type of the } \\
\text { carcinoma, } \mathrm{n}(\%)\end{array}$} \\
\hline Ductal & 2,097 (92.6) & $2,024(89.6)$ \\
\hline Lobular & $47(2.1)$ & $104(4.6)$ \\
\hline Mixed & $22(1.0)$ & $44(1.9)$ \\
\hline Other & $99(4.4)$ & $88(3.9)$ \\
\hline \multicolumn{3}{|l|}{$\begin{array}{l}\text { Grade of the primary } \\
\text { tumour, } n(\%)\end{array}$} \\
\hline 1 & $56(2.5)$ & $56(2.5)$ \\
\hline 2 & 787 (34.7) & $787(34.8)$ \\
\hline 3 & $1,425(62.8)$ & $1,421(62.8)$ \\
\hline \multicolumn{3}{|l|}{$\begin{array}{l}\text { Clinical stage at } \\
\text { diagnosis, } \mathrm{n}(\%)\end{array}$} \\
\hline I & 487 (22.6) & $553(25.5)$ \\
\hline II & $901(41.3)$ & $989(45.2)$ \\
\hline III & $560(25.7)$ & $483(22.1)$ \\
\hline IV & $226(10.4)$ & $157(7.2)$ \\
\hline \multicolumn{3}{|l|}{$\begin{array}{l}\text { Performance status (PS) } \\
\text { at start of trastuzumab } \\
\text { treatment, } \mathrm{n}(\%)\end{array}$} \\
\hline PS 0 & $1,244(72.4)$ & $1,422(77.1)$ \\
\hline PS 1 & $449(26.1)$ & $392(21.3)$ \\
\hline PS 2 or PS 3 & $25(1.5)$ & $30(1.6)$ \\
\hline \multicolumn{3}{|l|}{ Surgical treatment } \\
\hline No & $\mathrm{N}=147(6.9 \%)$ & $\mathrm{N}=112(5.2 \%)$ \\
\hline Yes & $\mathrm{N}=1,972(93.1 \%)$ & $\mathrm{N}=2,031(94.8 \%)$ \\
\hline \multicolumn{3}{|l|}{$\begin{array}{l}\text { Type of surgery (in those } \\
\text { who had surgical } \\
\text { treatment) }\end{array}$} \\
\hline Not indicated & $\mathrm{N}=5(0.3 \%)$ & $\mathrm{N}=2(0.1 \%)$ \\
\hline Ablation & $\mathrm{N}=1,109(56.2 \%)$ & $\mathrm{N}=1,000(49.2 \%)$ \\
\hline Conservative surgery & $\mathrm{N}=858(43.5 \%)$ & $\mathrm{N}=1,029(50.7 \%)$ \\
\hline \multicolumn{3}{|l|}{ Radiotherapy } \\
\hline No & $\mathrm{N}=651(31.3 \%)$ & $\mathrm{N}=567(27.1 \%)$ \\
\hline Yes & $\mathrm{N}=1,430(68.7 \%)$ & $\mathrm{N}=1,527(72.9 \%)$ \\
\hline \multicolumn{3}{|l|}{ Duration of follow-up (years) } \\
\hline Median $\left(5^{\text {th }}-95^{\text {th }}\right.$ percentile $)$ & $3.5(0.5-10.3)$ & $3.6(0.5-10.1)$ \\
\hline
\end{tabular}

included in the analysis after balancing the data by propensity score matching (R statistical software with MatchIt package) with respect to age ( $p=0.335$ after matching) and grade ( $p=0.998$ after matching). The propensity score matching analysis followed the population analysis in a previous manuscript by the same authors focused on comparison of patients' groups according to their ER and/or PR receptor status in the real-world settings (10). Classified according to their ER and/or PR receptor status, the two resulting groups contained approximately the same numbers of patients, patients with both ER- and PR-negative $(n=2,268)$ and patients with either ER or PR positive $(n=2,264)$. Patient characteristics are shown in Table I. 


\section{A All patients}

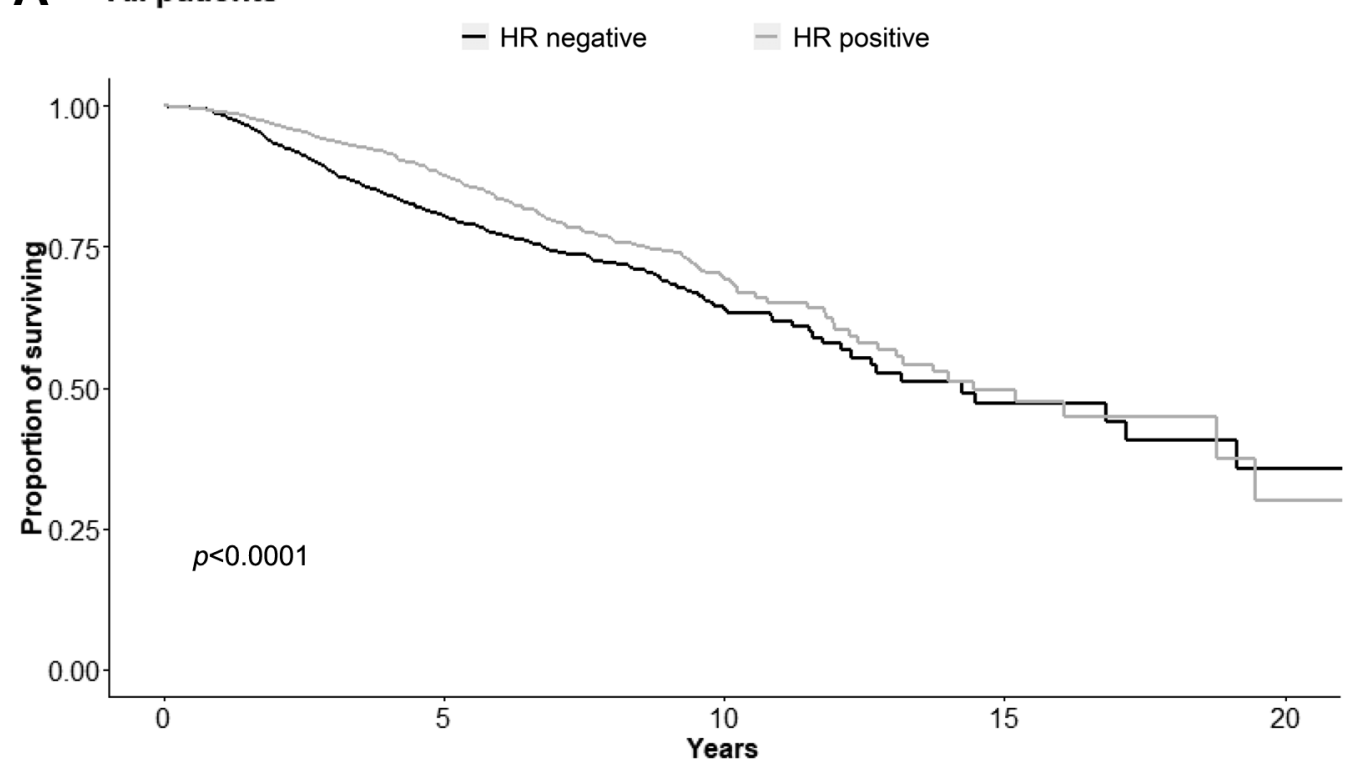

\section{Number at risk}

\begin{tabular}{|c|c|c|c|c|}
\hline 2268 & 845 & 145 & 22 & 7 \\
\hline 2264 & 801 & 120 & 24 & 4 \\
\hline 0 & 5 & $\begin{array}{c}10 \\
\text { Years }\end{array}$ & 15 & 20 \\
\hline
\end{tabular}

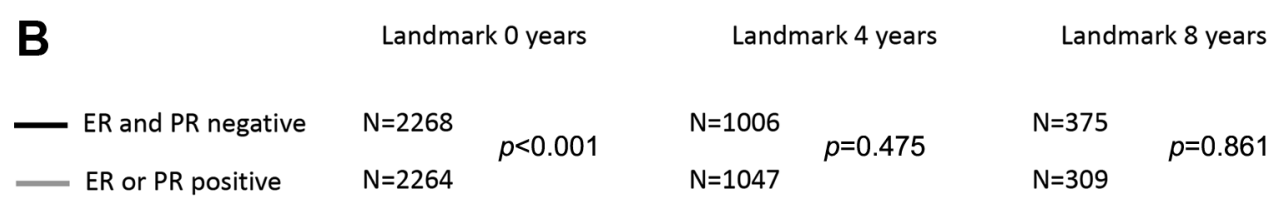

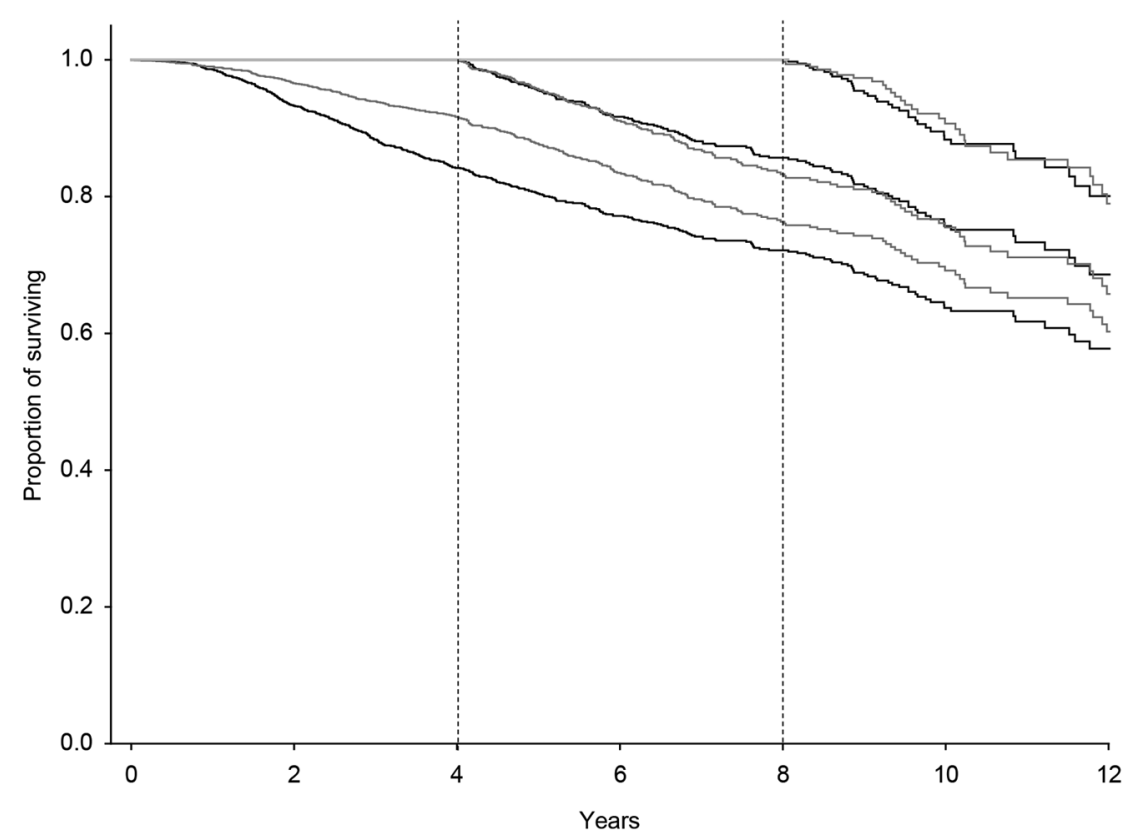

Figure 1. (a) Overall survival of patients according to HR positivity. (b) Landmark analysis in 0 , 4 and 8 years of overall survival according to HR positivity. 
Table II. Overall survival (OS) from the diagnosis according to patient groups.

\begin{tabular}{|c|c|c|c|}
\hline & HR negative $(n=2,268)$ & HR positive $(n=2,264)$ & $p$-Value* \\
\hline Median OS (95\% CI) & 14.2 years $(11.0-17.5)$ & 14.5 years $(12.1-16.9)$ & $<0.001$ \\
\hline 1 -year OS $(\% ; 95 \% \mathrm{CI})$ & $98.6(98.1-99.1)$ & $99.0(98.6-99.4)$ & \\
\hline 3 -year OS $(\% ; 95 \%$ CI $)$ & $88.3(86.8-89.9)$ & $93.9(92.8-95.1)$ & \\
\hline 5 -year OS $(\% ; 95 \%$ CI $)$ & $80.4(78.4-82.5)$ & $87.7(85.9-89.5)$ & \\
\hline Stratification & \multicolumn{2}{|c|}{$\begin{array}{l}\text { Hazard ratio }(95 \% \mathrm{CI}) \\
\text { for HR positive } v s . \mathrm{HR} \text { negative }\end{array}$} & $p$-Value ${ }^{\#}$ \\
\hline \multicolumn{4}{|l|}{ Grade } \\
\hline 1 & \multicolumn{2}{|c|}{$0.261(0.058-1.186)$} & 0.082 \\
\hline 2 & \multicolumn{2}{|c|}{$0.533(0.405-0.702)$} & $<0.001$ \\
\hline 3 & \multicolumn{2}{|c|}{$0.843(0.702-1.012)$} & 0.066 \\
\hline \multicolumn{4}{|l|}{ Stage } \\
\hline I & \multicolumn{2}{|c|}{$0.909(0.520-1.586)$} & 0.736 \\
\hline II & \multicolumn{2}{|c|}{$0.888(0.668-1.180)$} & 0.413 \\
\hline III & \multicolumn{2}{|c|}{$0.679(0.526-0.877)$} & 0.003 \\
\hline IV & \multicolumn{2}{|c|}{$0.651(0.478-0.885)$} & 0.006 \\
\hline
\end{tabular}

*Log-rank test. ${ }^{\#}$ Cox proportional hazards model.

Statistical analysis. Standard statistical methods were used to characterise the patient cohorts. Categorical variables were described using absolute frequencies and percentages, whereas continuous variables were described by median, minimum and maximum values. The statistical significance of differences between subgroups of patients was calculated using the Fisher's exact test (for categorical variables) or the Mann-Whitney test (for continuous variables).

The survival analysis was performed using the Kaplan-Meier (KM) method, and 95\% confidence intervals were calculated for all point estimates. The OS was calculated from the date of diagnosis to the date of death. Surviving patients were censored on the date of last update of the record in the research database. Survival rates of patient subgroups were compared using the log-rank test; the landmark analysis was adopted for the identifications of the cut-off time at which there is no significant difference between the OS curves of patient subgroups. Influence of patients' characteristics on survival was analysed using Cox proportional hazards model and described by hazard ratios and their $95 \%$ confidence intervals. All statistical tests were performed at the significance level $\alpha=0.05$ and computed using SPSS 22.0.0.1 (IBM Corp. Release 2013) (IBM SPSS Statistics for Windows, Version 22.0. Armonk, NY, USA).

\section{Results}

OS of the entire cohort of patients is shown in Figure 1a and Table II. A significant difference $(p<0.001)$ in OS can be clearly seen between the groups of patients with and without hormone receptors; the visual inspection of the KM curve reveals that patients with hormone receptor positive (HR+) tumours have a higher OS in the first several years of followup. Landmark analysis aimed on the comparison of the survival curves from given time points (the analysis does not take into account differences in survival curves before the analysed time point, but only further increase in difference) found that after four/five years the increase of difference between the curves stopped ( $p=0.475$ ) (Figure 1b).

OS results according to treatment are shown in Figure 2. Among patients treated in neoadjuvant setting, OS was significantly improved in patients with $\mathrm{HR}+$ tumours $(p=0.046)$. In the group treated for advanced disease, OS was significantly better in HR+ patients $(p=0.007)$.

Results of OS according to stage at diagnosis (Table II) have shown no significant differences in the OS between patients with $\mathrm{HR}+$ and hormone receptor negative (HR-) tumours who were diagnosed at stages I with $\mathrm{HR}=0.909$, 95\% $\mathrm{CI}=0.520-1.586, p=0.736$ and II with $\mathrm{HR}=0.888,95 \%$ $\mathrm{CI}=0.668-1.180, p=0.413$ respectively. As for patients diagnosed at stages III or IV, however, the OS was significantly higher in patients with HR+ tumours compared to patients with HR- tumours $(\mathrm{HR}=0.679,95 \% \mathrm{CI}=0.526$ $0.877, p=0.003$ and $\mathrm{HR}=0.651,95 \% \mathrm{CI}=0.478-0.885$, $p=0.006$ respectively). Evaluation of the significance of grade is shown in Table II. A significantly higher OS was only observed for grade 2 in $\mathrm{HR}+$ patients $(\mathrm{HR}=0.533,95 \%$ $\mathrm{CI}=0.405-0.702, p<0.001)$. The OS differences were not statistically significant in patients with grade $1(\mathrm{HR}=0.261$, 95\% CI $=0.058-1.186, p=0.082)$ and grade 3 tumours $(\mathrm{HR}=0.843,95 \% \mathrm{CI}=0.702-1.012, p=0.066)$, in grade 1 the low sample size should be taken into account, grade 3 shows trend for statistically significant difference.

When evaluating grade along with stage, a significantly improved OS was noted in grade 2 stage II, $p=0.021$ (Figure $3 a)$ and in grade 2 stage III patients with hormone receptorpositive tumours, $p=0.010$ (Figure $3 \mathrm{~b}$ ); there was a statistically significant difference between HR negative and positive in 
Neoadjuvant therapy

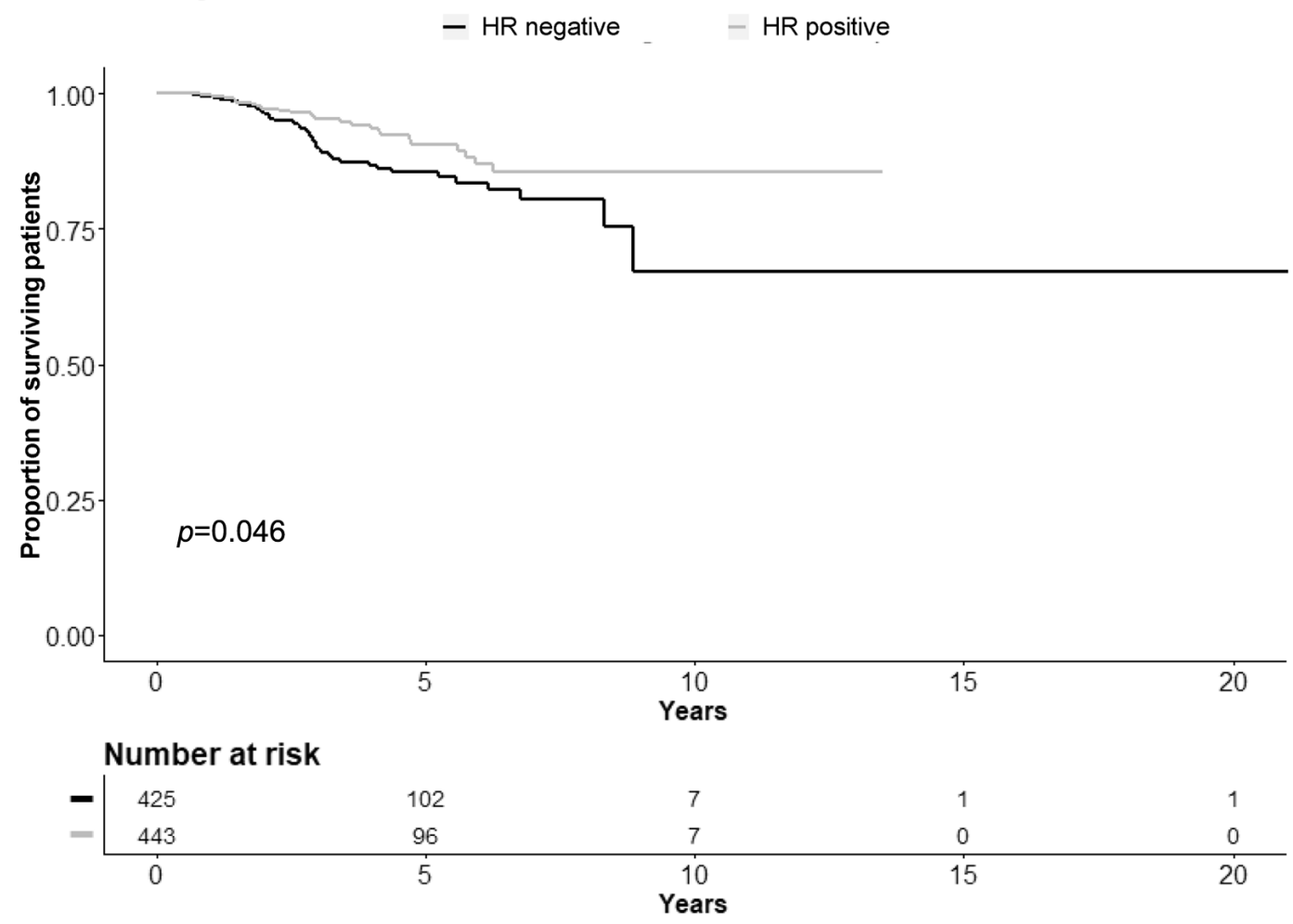

Advanced disease

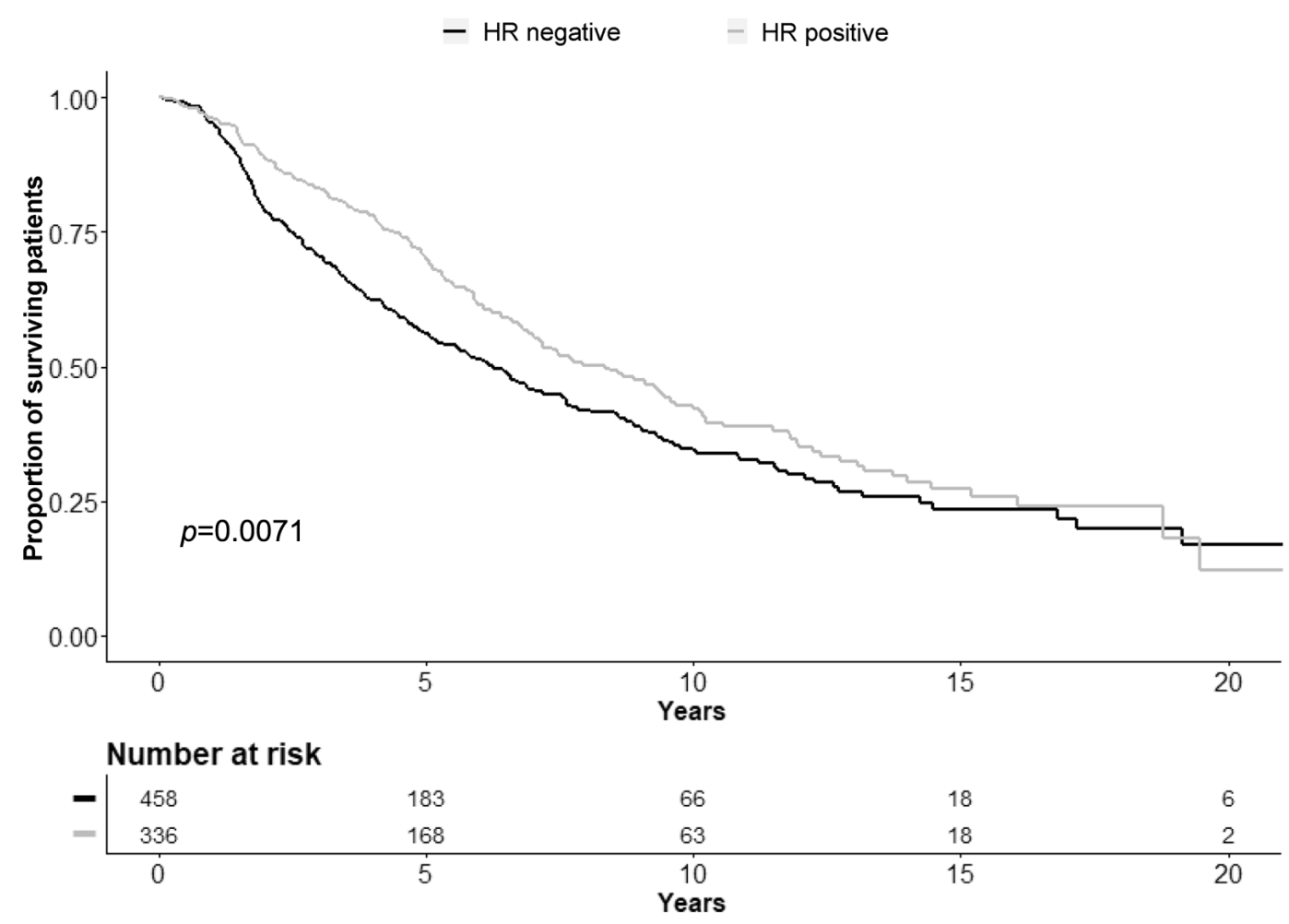

Figure 2. Overall survival according to HR positivity stratified by treatment. 

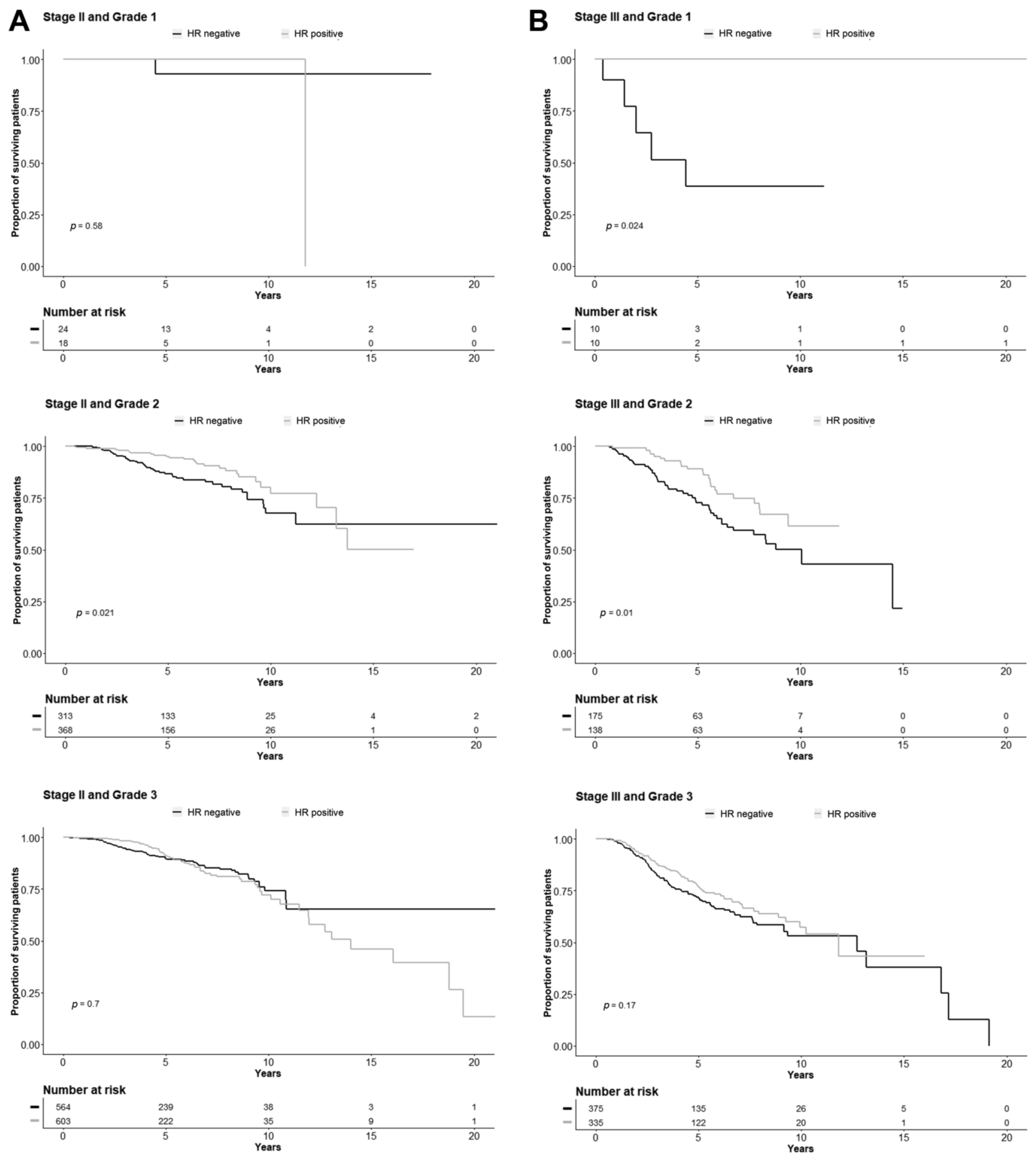

Figure 3. Overall survival according to HR positivity stratified by combination of stage and grade $(a, b)$.

stage III and grade 1 ( $p=0.024$, Figure $3 b)$, nevertheless due its sample size it should be interpreted with caution. One-, three- and five-year OS as well as the median OS and HR according to grade and stage are shown in Table II.

\section{Discussion}

In the present cohort of HER2+ breast cancer patients, increased OS rates were observed in several subgroups of 
patients with HR+ tumours compared to those with HRtumours. This difference was observed across the entire cohort of patients, in patients treated with neoadjuvant therapy, those treated for advanced disease, diagnosed at stage III or IV and patients with tumours in grade 2 diagnosed at stage II or III.

A large US study assessed OS differences of 196,094 breast cancer patients diagnosed between 2010 and 2013 included in the SEER cancer registry (11). The results showed that 4-year breast cancer-specific survival (BCSS) was slightly higher in patients with HR+/HER2- tumours when compared to patients with triple-positive tumours (92.5\% and $90.3 \%$ respectively), followed by patients with HR-/HER2+ tumours (82.7\%), and patients with triplenegative tumours $(77.0 \%)$. Stage at diagnosis was the strongest parameter determining OS. After four years of follow-up, OS was above $95 \%$ in patients diagnosed at stage I, regardless of the breast cancer subtype. Among patients diagnosed at stage IV, patients with the HR+/HER2+ subtype had the highest survival, also compared to patients with the HR+/HER2- tumours, even after controlling for other clinical and demographic parameters.

Regarding more advanced stages, our results showed a better prognosis for the cohort of TPBC patients compared to patients with HR-/HER2+ tumours as well. This lack of difference at earlier stages is probably also reflected in the absence of a significant OS difference between patients with HR+/HER2+ and HR-/HER2+ tumours treated with adjuvant therapy (i.e. those with earlier stages of disease). Unlike the results of the present study, results of adjuvant therapy in NCCTG N9831 and NCABP B 31 trials (12) showed a difference in survival between groups of patients with HER2+/HR+ and HER2+/HR- tumours who had been treated with adjuvant chemotherapy and trastuzumab, with being OS higher in TPBC patients. Patients in these trials, however, had positive lymph nodes or other risk factors, i.e. were higher-risk patients.

Interestingly, better outcomes in certain subgroups of TPBC patients were only observed in the first several years of follow-up, and the differences disappeared over time. Therefore, it cannot be ruled out that the long-term prognosis of HR+/HER2+ tumours might be less favourable than that of HR-/HER2+ tumours. This pattern of relapses corresponds to properties of luminal HR+ tumours $(13,14)$. In a study focused on operable breast cancer patients who were treated in International Breast Cancer Study Group clinical trials, patients with ER+ tumours (compared to those with ERtumours) had a lower annual hazard rate of relapse during the first five years after treatment completion, but beyond 5 years, patients with ER+ tumours had higher annual hazard rates (ER+ vs. ER- tumours: 5-10 years, 5.4\% vs. 3.3\%, 1015 years $2.9 \%$ vs. $1.3 \%$ and $15-20$ years $2.8 \%$ vs. $1.2 \%$ respectively) (14).
For highly hormone-dependent breast cancer, the efficacy of trastuzumab treatment is controversial in some TPBC patients. In a study reported by Vici et al., hormone receptor expression was identified as yet another factor that might affect the temporal distribution of relapses (15). The present retrospective analysis was focused on patients treated with adjuvant chemotherapy alone compared to patients treated with adjuvant chemotherapy plus trastuzumab, and relapsefree survival (RFS) and breast cancer specific survival (BCSS) were evaluated. The results revealed that the pattern of relapses was markedly different in the subgroup of patients whose tumours expressed HR in more than $50 \%$ of cells. Among these patients, the risk of relapse was low in the first five years, but a late increase was observed after this time compared to the group of patients with HR-tumours. The pattern of relapses in TPBC patients whose tumours expressed $\mathrm{HR}$ in $>50 \%$ of cells after adjuvant therapy is similar to that of luminal, HER2-negative tumours.

Data from a study that investigated the benefit of trastuzumab therapy in patients with advanced breast cancer indicated that a high expression of ER ( $\geq 30 \%$ of tumour cells) was associated with a decreased efficacy of trastuzumab and chemotherapy. However, the progressionfree survival (PFS) in patients with highly ER+ tumours was markedly improved if endocrine therapy was added (16).

Guidelines by both the American Society of Clinical Oncology (ASCO) and the European Society for Medical Oncology (ESMO) consider adding endocrine therapies to be justified as the maintenance therapy in TPBC patients in metastatic setting $(17,18)$.

We are aware of the limitations of the present retrospective analysis, which was performed using data from a population-based research database of patients treated with trastuzumab in the Czech Republic. Tumour grade, hormone dependence and HER2 status were determined in local laboratories, without being confirmed by a central laboratory. However, only reference laboratories (i.e. those which met strict standards required in the Czech Republic) were allowed to perform this task. The research database does not contain detailed information on treatment and other important data which could influence its outcomes, such as the medical history, comorbidities or lifestyle. Despite these limitations, data reflecting the outcome of a significant number of patients included in the presented analysis confirm trends observed in other studies.

Results of the present study have shown that HR+/HER2+ breast cancer represents a subgroup which has distinctive properties. Behaviour and treatment of this breast cancer subtype have not been sufficiently understood to date, and its prognosis is influenced by the fact that there is important crosstalk between ER and HER2 signalling pathways, which affects TPBC behaviour. TPBC tumors frequently belong to the luminal molecular subtypes and especially luminal A-like 
subgroup is associated with better prognosis and reduced benefit of trastuzumab $(19,20)$.

The advantage of the triple-positive subtype is the possibility to hit all therapeutic targets (HR and HER2), which may explain the superior OS results in advanced stages of the disease (21).

Better outcomes of TPBC patients were only found in the first four/five years of follow-up, but a late increase of relapses was observed after this time and the differences disappeared which corresponds to properties of luminal HR+ tumours.

\section{Conflicts of Interest}

The Authors declare no conflicts of interest with regard to the present study.

\section{Authors' Contributions}

Study concept and design: IK, LD, JV, JJ. Acquisition, analysis, and interpretation of data: IK, LD, BM, JP, TB, MV, KP, PT and JJ. Drafting of the manuscript, statistical analyses IK, BM, JV, LD, JJ. Investigation: all Authors.

\section{Acknowledgements}

The Authors would like to thank the following heads of comprehensive cancer centres for their permission to use data on patients from their respective regional networks: Rostislav Vyzula (Masaryk Memorial Cancer Institute, Brno), Luboš Petruželka (General University Hospital in Prague), Bohuslav Melichar (University Hospital Olomouc), David Vrana (Hospital Novy Jicin), Jiri Petera (University Hospital Hradec Králove), Jana Prausova (University Hospital in Motol, Prague), Jindrich Finek (University Hospital Plzen), Vaclav Janovsky (Hospital Ceske Budejovice), Jaroslav Vanasek (Multiscan and Hospital Pardubice), Jiri Bartos (Regional Hospital Liberec), Jakub Cvek (University Hospital Ostrava), Tomas Büchler (Thomayer Hospital, Prague), Lubomir Slavicek (Hospital Jihlava), Martina Chodacka (Masaryk Hospital Usti nad Labem and Hospital Chomutov), Milan Kohoutek (Tomas Bata Regional Hospital, Zlin), Jiri Mayer (University Hospital Brno), Renata Soumarova (University Hospital Kralovske Vinohrady, Prague), Lubos Petruzelka (Hospital Na Bulovce, Prague), Martin Safanda (Hospital Na Homolce, Prague), Jana Katolicka (St. Anne's University Hospital in Brno).The Authors are also indebted to all physicians who entered data into the database.

\section{References}

1 Osborne CK and Schiff R: Mechanisms of endocrine resistance in breast cancer. Annu Rev Med 62: 233-247, 2011. PMID: 20887199. DOI: 10.1146/annurev-med-070909-182917

2 Slamon DJ, Clark GM, Wong SG, Levin WJ, Ullrich and McGuire WL: Human breast cancer: correlation of relapse and survival with amplificationof the HER-2/neu oncogene. Science 235(4785): 177-182, 1987. PMID: 3798106. DOI: 10.1126/ science. 3798106

3 Giuliano M, Trivedi MV and Schiff R: Bidirectional crosstalk between the estrogen receptor and human epidermal growth factor receptor 2 signaling pathways in breast cancer: molecular basis and clinical implications. Breast Care 8(4): 256-262, 2013. PMID: 24415978. DOI: 10.1159/000354253

4 Spector NL and Blackwell KL: Understanding the mechanisms behind trastuzumab therapy for human epidermal growth factor receptor 2-positive breast cancer. J Clin Oncol 27(34): 58385847, 2009. PMID: 19884552. DOI: 10.1200/JCO.2009.22.1507

5 Moasser MM: The oncogene HER2; its signaling and transforming functions and its role in human cancer pathogenesis. Oncogene 26(45): 6469-6487, 2007. PMID: 17471238. DOI: 10.1038/sj.onc.1210477

6 Wu VS, Kanaya N, Lo C, Mortimer J and Chen S: From bench to bedside: What do we know about hormone receptor-positive and human epidermal growth factor receptor 2-positive breast cancer? J Steroid Biochem Mol Biol 153: 45-53, 2015. PMID: 25998416. DOI: 10.1016/j.jsbmb.2015.05.005

7 Prat A and Baselga J: The role of hormonal therapy in the management of hormonal-receptor-positive breast cancer with co-expression of HER2. Nat Clin Pract Oncol 5(9): 531-542, 2008. PMID: 18607391. DOI: $10.1038 /$ ncponc1179

8 Lousberg L, Collignon J and Jerusalem G: Resistance to therapy in estrogen receptor positive and human epidermal growth factor 2 positive breast cancers: progress with latest therapeutic strategies. Ther Adv Med Oncol 8(6): 429-449, 2016. PMID: 27800032. DOI: $10.1177 / 1758834016665077$

9 Howlader N, Altekruse SF, Li CI, Chen VW, Clarke CA, Ries LA and Cronin KA: US incidence of breast cancer subtypes defined by joint hormone receptor and HER 2 status. J Natl Cancer Inst 106(5): dju055, 2014. PMID: 24777111. DOI: 10.1093/jnci/dju055

10 Kolarova I, Vanasek J, Dolezal M, Stuk J, Hlavka A, Dusek L., Melichar B, Büchle T, Ryška A, Prausová J, Petrakova K, Tesarova P, Petera J, Vosmik M, Horacova K, Jarkovsky J: Association of triple positivity with prognostic parameters and overall survival in a population-based study of 6,122 HER2positive breast cancer patients: analysis of real-world clinical practice based on a research database. Neoplasma, 2020. PMID: 32614235. DOI: 10.4149/neo_2020_191023N1080

11 Howlader N, Cronin KA, Kurian AW and Andridge R: Differences in breast cancer survival by molecular subtypes in the United States. Cancer Epidemiol Biomarkers Prev 27(6): 619-626, 2018. PMID: 29593010. DOI: 10.1158/1055-9965.EPI$17-0627$

12 Chumsri S, Li Z, Serie DJ, Mashadi-Hossein A, Colon-Otero G, Song N, Pogue-Geile K, Gavin P, Paik S, Moreno-Aspitia A, Perez EA and Thompson EA: Incidence of late relapse in HER2positive (HER2+) breast cancer patients receiving adjuvant trastuzumab: Combined analysis of NCCTG (Alliance) N9831 and NSABP (NRG) B31 [abstract]. In: Proceedings of the 2018 San Antonio Breast Cancer Symposium; 2018 Dec 4-8; San Antonio, TX. Cancer Res 79(4Suppl): Abstract PD3-02, 2019. DOI: 10.1158/1538-7445.SABCS18-PD3-02

13 Colzani E, Liljegren A, Johansson AL, Adolfsson J, Hellborg H, Hall PF and Czene K: Prognosis of patients with breast cancer: causes of death and effects of time since diagnosis, age, and tumor characteristics. J Clin Oncol 29(30): 4014-4021, 2011. PMID: 21911717. DOI: 10.1200/JCO.2010.32.6462

14 Colleoni M, Sun Z, Price KN, Karlsson P, Forbes JF, Thürlimann B, Gianni L, Castiglione M, Gelber RD, Coates AS and Goldhirsch A: Annual hazard rates of recurrence for breast 
cancer during 24 years of follow-up: Results from the international breast cancer study group trials I to V. J Clin Oncol 34(9): 927-935, 2016. PMID: 26786933. DOI: 10.1200/ JCO.2015.62.3504

15 Vici P, Pizzuti L, Sperduti I, Frassoldati A, Natoli C, Gamucci T, Tomao S, Michelotti A, Moscetti L, Gori S, Baldini E, Giotta F, Cassano A, Santini D, Giannarelli D, Di Lauro L, Corsi DC, Marchetti P, Sini V, Sergi D, Barba M, Maugeri-Saccà M, Russillo M, Mentuccia L, D’Onofrio L, Iezzi L, Scinto AF, Da Ros L, Bertolini I, Basile ML, Rossi V, De Maria R and Montemurro F: "Triple positive" early breast cancer: an observational multicenter retrospective analysis of outcome. Oncotarget 7(14): 17932-17944, 2016. PMID: 26910921. DOI: 10.18632 /oncotarget.7480

16 Montemurro F, Rossi V, Cossu Rocca M, Martinello R, Verri E, Redana S, Adamoli L, Valabrega G, Sapino A, Aglietta M, Viale $\mathrm{G}$, Goldhirsch A and Nolè F: Hormone-receptor expression and activity of trastuzumab with chemotherapy in HER2-positive advanced breast cancer patients. Cancer 118(1): 17-26, 2012. PMID: 21598238. DOI: $10.1002 / \mathrm{cncr} .26162$

17 Giordano SH, Temin S, Kirshner JJ, Chandarlapaty S, Crews JR, Davidson NE, Esteva FJ, Gonzalez-Angulo AM, Krop I, Levinson J, Lin NU, Modi S, Patt DA, Perez EA, Perlmutter J, Ramakrishna N, Winer EP and American Society of Clinical Oncology: Systemic therapy for patients with advanced human epidermal growth factor receptor 2-positive breast cancer: American society of clinical oncology clinical practice guideline. J Clin Oncol 32(19): 2078-2099, 2014. PMID: 24799465. DOI: 10.1200/JCO.2013.54.0948

18 Cardoso F, Costa A, Senkus E, Aapro M, André F, Barrios CH, Bergh J, Bhattacharyya G, Biganzoli L, Cardoso MJ, Carey L,
Corneliussen-James D, Curigliano G, Dieras V, El Saghir N, Eniu A, Fallowfield L, Fenech D, Francis P, Gelmon K, Gennari A, Harbeck N, Hudis C, Kaufman B, Krop I, Mayer M, Meijer H, Mertz S, Ohno S, Pagani O, Papadopoulos E, Peccatori F, Penault-Llorca F, Piccart MJ, Pierga JY, Rugo H, Shockney L, Sledge G, Swain S, Thomssen C, Tutt A, Vorobiof D, Xu B, Norton L and Winer E: 3rd ESO-ESMO International Consensus Guidelines for Advanced Breast Cancer (ABC 3). Ann Oncol 28(1): 16-33, 2017. PMID: 28177437. DOI: 10.1093/annonc/ mdw544

19 Larionov AA: Current therapies for human epidermal growth factor receptor 2-positive metastatic breast cancer patients. Front Oncol 8: 89, 2018. PMID: 29670855. DOI: 10.3389/fonc. 2018.00089

20 Zhao S, Liu XY, Jin X, Ma D, Xiao Y, Shao ZM and Jiang YZ: Molecular portraits and trastuzumab responsiveness of estrogen receptor-positive, progesterone receptor-positive, and HER2positive breast cancer. Theranostics 9(17): 4935-4945, 2019. DOI: 10.7150/thno.35730

21 Swain SM, Baselga J, Kim SB, Ro J, Semiglazov V, Campone M, Ciruelos E, Ferrero JM, Schneeweiss A, Heeson S, Clark E, Ross G, Benyunes MC, Cortés J and CLEOPATRA Study Group: Pertuzumab, trastuzumab and docetaxel in HER2pozitive metastatic breast cancer. N Engl J Med 372(8): 724-734, 2015. PMID: 25693012. DOI: 10.1056/NEJMoa1413513

Received June 11, 2020

Revised July 15, 2020

Accepted July 20, 2020 